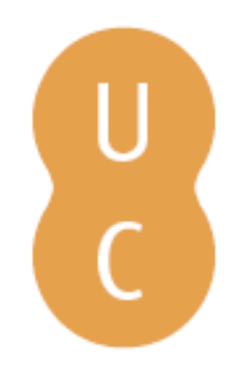

\title{
pommalina
}

\section{El mito de Antígona en Hedor Maldito de Gustavo Casanova}

Autor(es): Silventi, María Cristina

Publicado por: Centro de Estudos Clássicos e Humanísticos da Universidade de

URL

persistente: URI:http://hdl.handle.net/10316.2/30290

DOI: $\quad$ DOI:http://dx.doi.org/10.14195/978-989-721-038-9_60

Accessed : $\quad$ 26-Apr-2023 15:57:31

A navegação consulta e descarregamento dos títulos inseridos nas Bibliotecas Digitais UC Digitalis, UC Pombalina e UC Impactum, pressupõem a aceitação plena e sem reservas dos Termos e Condições de Uso destas Bibliotecas Digitais, disponíveis em https://digitalis.uc.pt/pt-pt/termos.

Conforme exposto nos referidos Termos e Condições de Uso, o descarregamento de títulos de acesso restrito requer uma licença válida de autorização devendo o utilizador aceder ao(s) documento(s) a partir de um endereço de IP da instituição detentora da supramencionada licença.

Ao utilizador é apenas permitido o descarregamento para uso pessoal, pelo que o emprego do(s) título(s) descarregado(s) para outro fim, designadamente comercial, carece de autorização do respetivo autor ou editor da obra.

Na medida em que todas as obras da UC Digitalis se encontram protegidas pelo Código do Direito de Autor e Direitos Conexos e demais legislação aplicável, toda a cópia, parcial ou total, deste documento, nos casos em que é legalmente admitida, deverá conter ou fazer-se acompanhar por este aviso.

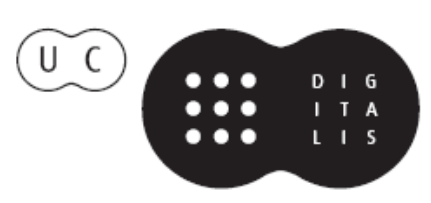




\section{De ayer a hoy}

\section{Influencias clásicas en la literatura}

\section{Aurora López, Andrés Pociña, Maria de Fátima Silva (coords.)}




\title{
El mito de Antígona en Hedor MaLdito de Gustavo Casanova.
}

\author{
María Cristina Silventi \\ Universidad de Cuyo
}

Las tragedias clásicas griegas de Esquilo, Siete contra Tebas y de Sófocles, Antígona, son recreadas por Gustavo Casanova en su obra Hedor maldito ${ }^{1}$. El autor, en una búsqueda constante de acercar al espectador la significación universal de los mitos griegos, selecciona y replantea aquellos pasajes de los dos trágicos que le permiten llevar a escena las secuencias principales del ciclo tebano. Valioso es, también, su aporte original al exhibir cuadros inéditos, como el enfrentamiento y muerte de los hermanos, así como las consecuencias de la maldición, llevadas a un primer plano a través de un tratamiento novedoso del coro que, al mismo tiempo, observa y narra los acontecimientos desencadenantes, mientras los personajes despliegan con lenguaje gestual sus palabras.

Con la convicción de que toda obra que recrea los motivos dramáticos griegos y latinos hace un nuevo aporte a la tradición clásica, me propongo presentar esta breve pieza del dramaturgo mendocino Gustavo Casanova 2 . Realizaré un breve análisis comparativo de esta versión con la de Esquilo, Siete contra Tebas y la de Sófocles, Antígona. Veremos que la novedad principal consiste en el uso que este escritor hace del lenguaje verbal y gestual con el ánimo de hacer comprensible un mito alejado del presente del espectador.

${ }^{1}$ El título de la obra está inspirado en las palabras proféticas que Tiresias le anuncia

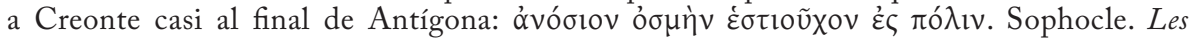
Trachiniennes. Antigone. Texte établi par Alphonse Dain et traduit par Paul Mazon. Paris: Société D’ Édition “Les Belles Letres”, 1955. v.1083, "aroma impuro por los altares de la ciudad” Sófocles. Antígona. Madrid: Gredos, 1992. p. 289, solo que aquí el "hedor” no es "impuro" tal como lo cualifica Sófocles para referirse al cadáver insepulto de Etéocles, sino que es "maldito". La imagen así expresada condensa y anticipa el motivo principal de la pieza.

${ }^{2}$ Gustavo Casanova (1966): Licenciado en Comunicación Social. Facultad de Ciencias Políticas y Sociales. UnCuyo. Licenciado en Arte Dramático. Facultad de Arte. UnCuyo. Actualmente cursa el Doctorado en Artes, especialidad Teatro, en la Universidad de Córdoba. Ha realizado su formación actoral con importantes maestros nacionales e internacionales. Como actor ha participado en más de 25 obras teatrales. Como director comenzó en el 2000 en el elenco "Las sillas" y en el 2005 fundó el grupo "Los Gregoristas" Como escritor ha producido siete obras teatrales. Actualmente es profesor Adjunto de la cátedra "Expresión Corporal" de la Universidad Juan Agustín Maza y profesor Adjunto de la cátedra "Actuación II" de la Licenciatura y el Profesorado de Arte Dramático. UnCuyo. 


\section{El argumento de la tragedia}

La historia, centrada en los hijos de Edipo, comienza con el motivo de la guerra entre tebanos y argivos y el enfrentamiento y muerte de Etéocles y Polinices. Sus hermanas se lamentan frente a los cadáveres y resuelven enterrarlos junto a la tumba de su padre. Pero un mensajero les anuncia la resolución de los magistrados del pueblo que prohíben el entierro de Polinices. A pesar de que Creonte ${ }^{3}$, que ostenta el mando de la ciudad, ordena respetar lo decretado y declara que hará pagar con su vida a aquel que desobedezca, Antígona resuelve llevar a cabo los ritos necesarios para dar digna sepultura a su hermano. Es descubierta por los guardias y Creonte la condena a permanecer en una caverna con escaso alimento hasta su muerte. El hijo de Creonte, Hemón, prometido de Antígona, enfrenta a su padre, pero ante la obstinación de este, se dirige hacia donde está Antígona sepultada en vida. Tiresias, la adivina, anticipa a Creonte nuevas desgracias, si no se retracta de su decisión. Temeroso, Creonte trata de reparar sus acciones, pero ya es demasiado tarde. No solo Antígona ha muerto, sino también su hijo y su esposa, Eurídice.

\section{Las fuentes principales}

Para recrear el mito Casanova se basó en las dos fuentes antes mencionadas. De Esquilo tomó la lucha entre hermanos, las endechas de las hermanas ante la muerte de estos y la resolución de Antígona de enterrar a su hermano pese a lo decretado. De Sófocles recreó el protagonismo de Antígona, la figura despótica de Creonte, Hemón y el coro de ancianos. Veamos cada tragedia en particular.

\section{Siete contra Tebas de Esquilo}

De esta tragedia Casanova ha tomado los primeros momentos del inminente ataque contra Tebas y nos presenta al coro y a Etéocles discutiendo sobre esta situación. El autor ha desplazado al coro temeroso de las jóvenes tebanas y, en su lugar, ha colocado al de ciudadanos de la Antígona de Sófocles, que permanecerá en el transcurso de toda la obra y que, en esta primera escena, desempeña un papel principal, puesto que a través de él se conocen las predicciones de la adivina ${ }^{4}$ y los preparativos bélicos de los argivos ${ }^{5}$. En

\footnotetext{
${ }^{3}$ Hermano de Yocasta y por lo tanto tío de los hijos de Edipo.

${ }^{4} \mathrm{El}$ remplazo de Tiresias por una mujer, fue una elección funcional, pues dentro del elenco contaban con una actriz que se adecuaba al papel. Entrevista con Gustavo Casanova. Junio 2011.

${ }^{5}$ En realidad, el coro en toda la pieza se adecua a la función que Aristóteles en su Poética

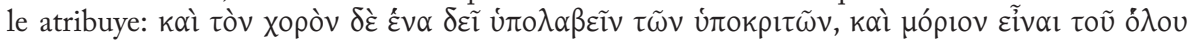


sus parlamentos reconocemos enunciados e imágenes que, en la tragedia de Esquilo, son expresadas por otros personajes. Así, por ejemplo, en la primera intervención utiliza palabras del Etéocles esquiliano: "Coro: - Señor, hasta ayer los dioses se inclinaban hacia nosotros benignos"7. Y más adelante hace suyas las palabras del espía8: - "Coro: Siete caudillos desollaron un toro sobre un herrado escudo. [...] Esos hombres impetuosos mojaron sus manos en sangre y juraron ávidos de venganza, asolar la ciudad y devastar la fortaleza de Cadmo".

Toma, además, muchas imágenes pronunciadas por el coro de jóvenes tebanas como, por ejemplo, "El aire brama enfurecido por lanzas"10, "el choque de los escudo"" 11 , entre otras, que hacen referencia al avance del enemigo hacia los muros.

Por otra parte, la larga tirada de versos que Esquilo emplea para el intercambio dialógico entre Etéocles y el mensajero y que le sirve para destacar a cada uno de los caudillos de ambos bandos, se ve reducida aquí a un breve discurso, de neto carácter apelativo, con el que el coro termina por convencer a Etéocles para que se disponga a la lucha:

Coro: -"Escucha esto y terminarás de convencerte. Cada uno de esos siete tiene asignado entrar a la ciudad por cada una de sus siete puertas. y lo más curioso es que por la última está tu propio hermano, Polinices, que vocifera que te matará o que, si vives, te hará conocer el destierro que tú le has hecho padecer"12.

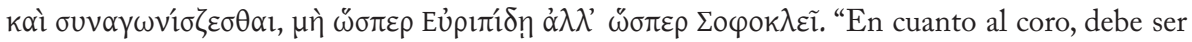
considerado como uno de los actores, formar parte del conjunto y contribuir a la acción, no como en Eurípides, sino como en Sófocles”. Poética. Aristóteles. Madrid: Gredos, 1992.1456 a 25.

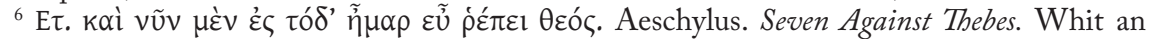
english translation by Herbert Weir Smyth, Ph. D., Eliot. The Loeb Classical Library. London: William Heinemann, Cambridge, Massachusetts: Harvard University Press, MCMLVI. In two volumes. T.I.v. 21 "Por el momento, hasta el día de hoy, la divinidad se inclina a nuestro favor". Tragedias, Esquilo, Madrid, Gredos, 1982, p. 56.

${ }^{7}$ Hedor maldito. Gustavo Casanova. Inédita, p. 1.

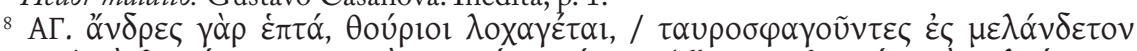

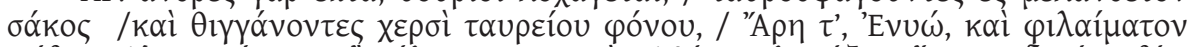

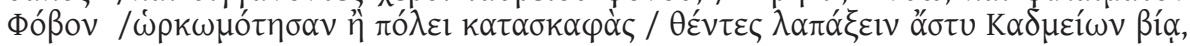
Aeschylus, op.cit. v. 41-46. "Siete héroes, valerosos caudillos, degollaban un toro, dejando que la sangre fluyera sobre un negro escudo; y, con sus manos tocando la sangre del toro, por Ares, por Enio y por Fobo sediento de sangre, juraron o bien destruir nuestra ciudad y saquear con violencia esta ciudad de los cadmeos, [...]”. Esquilo, op. cit., p. 56.

${ }^{9}$ Loc. cit.

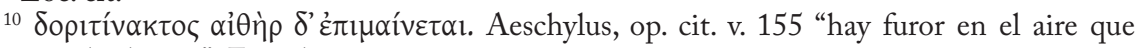
atraviesan las lanzas", Esquilo, op. cit. p., 61.

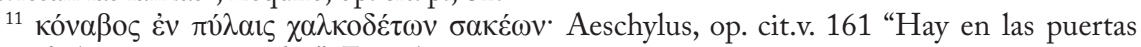
fragor de broncíneos escudos", Esquilo, op. cit., p. 62.

${ }^{12}$ Casanova, Gustavo, op. cit., p. 1. 
Vemos en todos los ejemplos que el coro, al mismo tiempo que informa a Etéocles de la situación, está cumpliendo la función que García Barrientos llamó "presentador del mundo ficticio"13 ante el espectador. Es más, podemos apreciar en sus discursos comprimidos la preocupación del autor por dar a conocer al público datos relacionados con el mito que le permitirán comprender más profundamente la representación. Esta vocación de hacer inteligible el mito la observamos también en las palabras de Etéocles, cuando reconoce que la guerra es consecuencia de la maldición de su padre: "Et: -Oh dioses tutelares, ¿acaso van a dar curso a la maldición de mi padre?" ${ }^{14} \mathrm{Y}$ en la última parte de la primera escena, en donde las palabras del mensajero esquiliano, que relatan el enfrentamiento y muerte de los hermanos, se ven aquí concretamente representadas. Durante la lucha los hermanos se agreden verbalmente y los dos mencionan el odio como el motivo principal de su enfrentamiento. Este sentimiento estará presente hasta el final de la obra y servirá de contraste para resaltar al personaje de Antígona: "Etéocles: -Ay, Polinices, eres merecedor del nombre que tienes ${ }^{15}$. Con el odio no conseguirás nada, con el odio no se gobierna. Polinices: -Es este odio que tanto rechazas, mi impulso para darte muerte"16.

De Esquilo toma también la escena de Antígona e Ismene que, con breves versos alternados, se lamentan ante los cadáveres de sus hermanos ${ }^{17}$. Nuevamente observamos un lenguaje simplificado, de tono actual, estructurado de manera contrastante, que nos recuerda el oximoron sofocleo: "Antígona Herido, heriste. Ismene - Has muerto, habiendo matado"18.

Finalmente, Casanova hace suya la versión de Esquilo que propone la tumba de Edipo en Tebas y no en Colono, como refiere Sófocles en su tragedia Edipo en Colono y se vale de algunos fragmentos de la discusión entre el mensajero y Antígona para presentar el decreto y la postura rebelde de la joven.

\section{Antígona de Sófocles}

El prólogo de la tragedia de Sófocles es recreado aquí con las mismas funciones clásicas. Por medio del diálogo entre Ismene y Antígona el autor

${ }^{13}$ García Barrientos, José Luis, Teoría de la Literatura y Literatura comparada. Cómo se comenta una obra de teatro, Madrid, Síntesis, 2003, p. 42.

${ }^{14}$ Casanova, Gustavo, op. cit., p. 1.

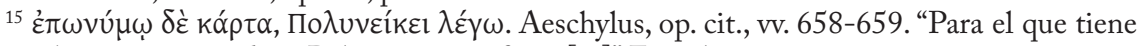
un nombre tan apropiado, a Polinices me refiero, [...]” Esquilo, op. cit., p. 82.

${ }^{16}$ Casanova, Gustavo, op. cit., p. 2.

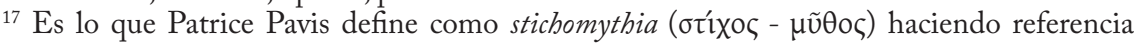
al rápido intercambio (algunos versos, frases o palabras) entre dos personajes y que logra un momento particularmente dramático, Pavis, Patrice, Diccionario del teatro. Dramaturgia, estética, semiología, Buenos Aires, Paidós, 1990, p. 188.

${ }^{18}$ Casanova, Gustavo, op. cit., p. 2. 
pone al tanto al espectador de aquellos datos que terminan de configurar el mito: la ceguera de Edipo, la relación incestuosa, la muerte de Yocasta y Edipo. Al mismo tiempo, define la posición de las hermanas y prepara el terreno para las escenas siguientes.

Desde este momento la obra presenta una gran semejanza en el contenido y en la trama con la tragedia de Sófocles, sin embargo Casanova hace un nuevo uso de pasajes claves, además de suprimir las partes líricas del coro y de emplear un tono actual, casi coloquial. Inclusive los extensos parlamentos de los personajes están reducidos con el fin de relevar el mensaje esencial. Así, por ejemplo, el extenso monólogo sofocleo, que abarca desde el verso 161 al $210^{19}$, es reducido aquí a unas cuantas palabras evitando las argumentaciones sobre el poder y los detalles del decreto: "Creonte - Ya conocen mi decisión. Por mí, nunca tendrán los criminales el honor que corresponde a los ciudadanos justos; por mi parte tendrán honores aquellos que cumplan con el estado, tanto en la muerte como en la vida"20.

En la recreación de las escenas entre el guardián y Creonte también advertimos una selección que pone en primer plano lo más significativo con respecto al mito ${ }^{21}$ : a) el ritual del muerto: "Guardia - Es que vino alguien que enterró al muerto, hace poco, echó sobre su cuerpo árido polvo y cumplió los ritos necesarios"; b) el imperio despótico de Creonte: "Creonte - [...] Y sé que hay gente en la ciudad que en secreto contra mí murmuran y agitan su cabeza, porque no soportan mis órdenes" y c) la responsabilidad de Antígona: "Guardia - Estaba enterrando al muerto: ya lo sabes todo".

Este carácter selectivo se observa también en las intervenciones del coro: "Coro - Es prudente lo que dices"22 y en las respuestas de Hemón a su padre: "Hemón - Entonces gobierna una ciudad desierta ${ }^{23 "}$.

Además de resignificar el lenguaje, Casanova realiza aportes con profundo valor expresivo, como por ejemplo, las palabras que dirige el corifeo a Antígona, cuando se dirige hacia su destino final: "Coro - Ilustre y alabada te marchas por tu propia decisión, fiel a tus leyes, en vida y sola, desciendes entre los muertos" 24 .

En función de los caracteres de los personajes y para profundizar la fuerza dramática, resalta frases proverbiales de Sófocles, pero reducidas a la mínima

${ }^{19}$ Sófocles, op. cit., pp. 255-257.

${ }^{20}$ Casanova, Gustavo, op. cit., p. 5.

${ }^{21} \mathrm{Ha}$ suprimido el discurso de Creonte sobre el dinero, la descripción que hace el guardia sobre cómo descubrieron a Antígona, etc.

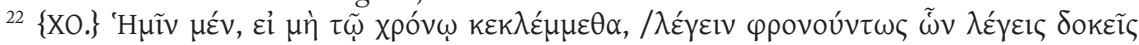
$\pi \varepsilon ́ p 1$. Sophocle, op. cit., v. 681. "A nosotros, si no estamos engañados a causa de nuestra edad, nos parece que hablas con sensatez en lo que estás diciendo”, Sófocles, op. cit., p.274.

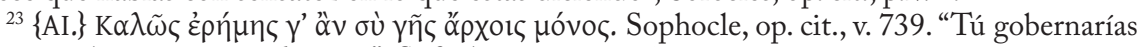
bien, en solitario, un país desierto", Sófocles, op. cit., p.276.

${ }^{24}$ Casanova, Gustavo, op. cit., p. 276. 
expresión. Así, por ejemplo, el célebre verso dicho por Antígona 25 "Antígona - No nací para compartir el odio, sino el amor"26, o las palabras con las que Hemón responde a su padre ${ }^{27}$ : "Hemón - No puede una ciudad, ser solamente de un hombre" 28 , o la respuesta que da Ismene ${ }^{29}$ a Antígona que la describe en su fragilidad: "Ismene - No seas atrevida: si las cosas están así, ate yo o desate en ellas, ¿qué podría ganarse?”30. Esta última expresión, con su valor literal, volvemos a encontrarla en boca de Creonte casi al final de la obra para expresar la misma impotencia, aunque irónicamente, aún no lo sabe: “Creonte - [...] En cuanto a mí, lo que yo mismo até, quiera yo al presente desatar" ${ }^{31}$.

\section{La originalidad del autor}

Respecto de la representación trágica Roland Barthes nos hace el siguiente comentario:

"Cada vez que nosotros, hombres modernos, tenemos que representar una tragedia antigua, nos hallamos ante los mismos problemas, y cada vez aportamos, para resolverlos, la misma buena voluntad y la misma incertidumbre, el mismo respeto y la misma confusión" ${ }^{32}$.

Con dificultades semejantes se encuentra quien recrea fuentes clásicas, pues estas han permanecido en la tradición con la fuerza inalterable de su valor literario, legitimadas por su vigencia. El odio de la guerra, el peso del poder, el respeto a los valores son temas que pueden retomarse en cualquier época y replantearse en cada contexto con igual intensidad.

$\mathrm{El}$ autor de Hedor maldito ha retomado el eje conflictivo tradicional que es el abuso de poder y el valor de las leyes ancestrales, representados en Creonte y Antígona respectivamente. En "duelo oratorio" ${ }^{33}$ se presentan dos concepciones del mundo, dos tipos de moral irreconciliables.

Para reactualizar el drama clásico y hacer inteligible el mito al espectador,

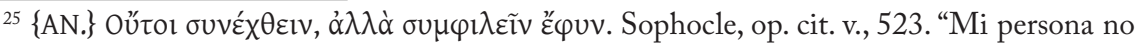
está hecha para compartir el odio, sino el amor", Sófocles, op. cit., p. 268.

${ }^{26}$ Casanova, Gustavo, op. cit., p. 9.

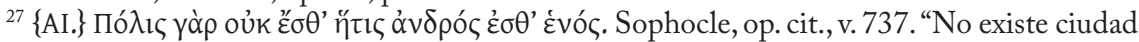
que sea de un solo hombre", Sófocles, op. cit., p. 276.

${ }^{28}$ Casanova, Gustavo, op. cit., p. 13.

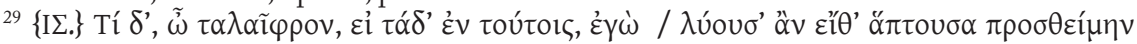

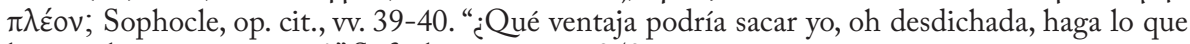
haga, si las cosas están así?” Sófocles, op. cit., p. 250.

${ }^{30}$ Casanova, Gustavo, op. cit., p. 4.

${ }^{31}$ Casanova, Gustavo, op. cit., p. 18.

${ }^{32}$ Barthes, Roland, Ensayos Criticos, Barcelona, Seix Barral, 1967, p. 87.

${ }^{33}$ Pavis, Patrice, op. cit., p. 93. 
Casanova propone un texto renovado, producto del ensamble de dos tragedias de las que ha seleccionado los pasajes que son significativos para entender el mito y los ha empleado como "motivos dinámicos" 34 , de modo que, al mismo tiempo que esclarecen, permiten el avance de la acción.

Para evitar el exceso de información que podría desviar la atención del espectador, ha suprimido las extensas intervenciones del coro e inclusive ha reducido y resaltado de los parlamentos de los personajes principales solo los que funcionan como recurso configurador de sus caracteres. Además, el tono actual casi coloquial con los que recrea los diálogos trae al presente el motivo clásico, le da vigencia y mantiene el interés del espectador.

En cuanto al espacio y el vestuario, el autor presentó una estructura vertical como símbolo de la idea de poder y propuso vestimentas con ribetes de contemporaneidad y estilos orientales (es el caso de Etéocles y Polinices), si bien también ha respetado "algunos elementos que responden al imaginario que la gente tiene de lo griego, como las espadas, cascos y escudos” 35 .

Con un tratamiento novedoso y cargado de dramatismo el autor resuelve la pieza y aporta una pincelada personal al mito. Así vemos que el parlamento del mensajero, que tradicionalmente relataba las escenas de muerte, pues en el contexto religioso de la tragedia no estaba permitido, es desglosado aquí en un lenguaje gestual fuertemente representativo. El mensajero comienza a relatar, pero luego es el coro quien asume protagonismo y continúa narrando al mismo tiempo que sirve de espectador de la escena que reproducen Creonte, el mismo mensajero y luego Hemón y su madre. Eurídice, silenciosa en la obra de Sófocles, interviene activamente mientras repite con compás enajenado su maldición contra los Labdácidas. La escena constituye una innovación ${ }^{36}$ que coloca al espectador frente a una representación dentro de otra representación, donde las palabras del coro se completan visualmente con la actuación de los personajes. El momento de mayor dramatismo se presenta en ese instante en que la espada une en una sola imagen la muerte de la madre y el hijo ante la mirada impotente de Creonte. El cuadro final constituye el aporte más original del autor, porque resuelve en una metáfora visual los últimos momentos de este pasaje del mito resignificando su valor como verdad universal.

${ }^{34}$ Pavis, Patrice, op. cit., p. 325.

${ }^{35}$ Casanova, Gustavo, Entrevista con el autor, junio 2011.

${ }^{36} \mathrm{Al}$ respecto, el autor relaciona esta escena con el cine y la voz en off, planteada como el traspaso de voces: el mensajero cede la voz al coro que narra en off los hechos que suceden en la caverna y lo que pasa en palacio. El espectador ve la escena como si se tratara de un montaje paralelo. Entrevista con el autor, junio 2011. 


\section{Bibliografía}

Abraham, Luis Emilio, Escenas que sostienen mundos. Mimesis y modelos de ficción en el teatro, Prólogo de García Barrientos, Madrid, Consejo Superior de Investigaciones Científicas, 2008.

Barthes, Roland, Ensayos Críticos, Barcelona, Seix Barral, 1967.

Bobes Naves, M. C. y otros, Teoría del teatro, por M. C. Bobes Naves, M. Corvin, J. L.García Barrientos, R. Ingarden, S. Jansen, T. Kowzan, M. Procházka, J. M. Thomasseau, J. Veltrusky, Madrid, Arco, 1997.

Brecht, Bertolt, Escritos sobre teatro, Selección de Jorge Hacker, Trad. de Nélida Mendilaharzu de Machain, Buenos Aires, Ediciones Nueva Visión, 1970.

Castagnino, Raúl, Teoría del teatro, Buenos Aires, Nova, s.f.

López Férez, J. A. (ed.) Historia de la literatura griega, Madrid, Cátedra, 1988.

Rest, Jaime, El teatro moderno, Buenos Aies, Centro Editor de América Latina, 1967.

\section{Fuentes}

Casanova, Gustavo, Hedor maldito, Sin publicar.

Aeschylus, Seven Agaisnt Thebes, With an english translation by Herbert Weir Smyth, Ph.D., Eliot, The Loeb Clasical Library, London, William Heinemann, Cambridge, Masachusetts, Harvard University Press, 1956, T. I.

Esquilo, Tragedias, Trad. y notas de B. Perea, Intr. general de F. Rodríguez Adrados, Madrid, Gredos, 1982.

Sophocle, Les Trachiniennes. Antigone, Texte établi par Alphonse Dain et traduit par Paul Mazon, Paris, Société d'Édition "Les Belles Letres".

Sófocles, Tragedias, Intr. de José Lasso de la Vega. Trad. y notas de Assela Alamillo, Madrid, Gredos, 1992. 